\title{
Lobbying for and against climate solutions
}

\author{
New voices in the climate movement appear keenly aware that they face well-funded, long-entrenched interests \\ inhibiting sensible climate change policy. Getting a grip on when and how lobbying impacts policy is key to \\ translating calls for 'climate action' into feasible policies.
}

T he climate movement that has formed under the \#FridaysforFuture and \#YouthStrike4Climate monikers has gained global media attention and been encouraged by policymakers at the highest level. The students who have engaged in a variety of social movement tactics (such as sit-ins, walkouts and strikes) are demanding governments take action on the climate crisis. The movement has in many ways cast itself as fighting against entrenched interests. In many places, climate policy has stalled or simply failed to start, something the movement seeks to change, but because the movement is global and decentralized it lacks specific policy demands. Thus, it begs the question of what kinds of policies are likely to succeed in the face of domestic political barriers.

One such political barrier is organized lobbying. Extensive lobbying has emerged around climate policies in the United States, as well as the European Union. While climate change politics is generally depicted as occurring between an anti-climate industrial lobby and a non-governmental pro-environmental lobby, the distributional consequences of policies means that businesses adopt a variety of political strategies. Certainly, fossil-fuel companies, utilities and transportation-related businesses have reasons to lobby against climate policy in the broad sense, but the reality is more nuanced. For example, $\mathrm{BP}$ and other UK power firms were influential in mobilizing support for the European Emissions Trading Scheme ${ }^{1}$. Nonetheless, it is often difficult to explain why a particular mix of policies has been enacted or what policy design changes might increase the likelihood of enactment. Rarely is there enough information available to quantify the impact of corporate lobbying expenditures on specific policies.

Recent research has estimated that in the United States, between 2000 and 2016, more



Credit: Sesame/DigitalVisionVectors/Getty

than US $\$ 2$ billion was spent on lobbying around climate issues ${ }^{2}$. In this issue, Kyle Meng and Ashwin Rode quantify the impact of political lobbying around the American Clean Energy and Security Act, the most high-profile federal climate legislation to date. This legislation, informally known as the Waxman-Markey bill in reference to its two key sponsors, featured an emissions cap-and-trade scheme. It passed in the US House of Representatives in the summer of 2009, but ultimately failed in the Senate when the Congressional term expired in 2010. Meng and Rode estimate that lobbying against the bill between July 2009 and the end of 2010 reduced the probability of passage from $55 \%$ to $42 \%$, representing a welfare loss of US $\$ 60$ billion. Arriving at these estimates is a unique challenge.

It is reasonable to believe that firms who stand to lose (or gain) the most are the biggest lobbyers, but in the case of climate policy it may not be obvious who gains and who loses from firm characteristics alone. For example, while the coal industry might oppose a climate bill, utility industry firms with differing generation portfolios may actually favour a cap-and-trade scheme that allots emissions permits in a particular way over other renewable energy directives ${ }^{3}$. Here, Meng and Rode let the market do the talking. By combining stock and prediction market data they are able to determine how the proposed policy affects a firm's stock values, and thus whether it stands to win or lose from the policy. This information is then combined with a game-theoretic model of lobbying to determine how the effect of lobbying varies with lobbying amounts, and with respect to gaining and losing firms.

As Fabien Prieur describes in the accompanying News \& Views, one interesting finding from Meng and Rode is that lobbying was more effective for firms expecting to lose under the pending policy. Further research is needed to better understand why this was the case, but one hypothesis is that groups standing to lose have longer lobbying histories and thus have developed mutually beneficial relationships with politicians. This explanation certainly resonates with work documenting the role of fossil fuel firms in funding climate skepticism and misinformation campaigns $\mathbf{s}^{4,5}$.

It is well understood that support for climate policies depends on institutional design. This effect is particularly notable with respect to market-based policies such as cap-and-trade and carbon taxation, but it also suggests there are ways to manage the distributional effects of policy in such a way that turns entrenched opponents into policy proponents.

Published online: 28 May 2019 https://doi.org/10.1038/s41558-019-0499-4

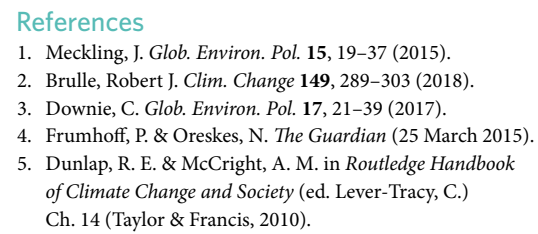

